\title{
Development and classification of Heave Compensation Technology
}

\author{
Wu Junjie ${ }^{1}$, Ji Yang $^{1}$, Chen Haiquan ${ }^{1, a},{ }^{1}$ Li Wenhua ${ }^{1}$, Zhang Renzhi ${ }^{1}$, Jiang Dong $^{2}$
}

(1.Dalian Maritime University, Liaoning Dalian 116026;

2.China Classification Society, Qingdao 266000)

('email:18580122017@163.com)

\begin{abstract}
Keywords: heave compensation; deep sea mining system; heave compensation system of ROV; heave compensation system of drill string; heave compensation system of ship crane

Abstract: Under the influence of marine environment such as wind, wave and current, the lifting movement in the vertical direction will be produced. Heave movement will not only affect normal operations, but also lead to serious safety accidents and environmental pollution. The research object of the technology of heave compensation is the motion of the ship in the vertical direction. It can compensate the influence of the lifting of the ship lift to the lifting weight, so that it can operate normally in the bad sea condition. This paper introduces the history of the technology of heave compensation and the status of the research at home and abroad firstly. Then according to the different purposes of the mainstream of the compensation scheme for classification. To lay the foundation for the development of the heave compensation technology.
\end{abstract}

\section{Introduction}

The vast ocean contains rich oil, gas and mineral resources, with the rapid development of China's national economy, The country's dependence on the ocean has increased significantly.

Developing and using marine space and marine resources has become important support points for the development of the national economy. But ships will produce six-degrees of freedom under the action of ocean winds, waves and currents during operations. This will not only affect the normal operation, but also lead to serious safety accidents and environmental pollution, resulting in loss of life and property. In recent years, with the use of dynamic positioning systems, People can control the thrust system to distribute the thrust of each thruster so that the ship can continue to set the heading and position under the interference of wind, waves and currents. However, the dynamic positioning system can only compensate for the three-degrees-of-freedom movement of the ship, such as swaying, surging, and yawing. It is impossible to compensate for the heave motion in the vertical direction. This requires a special heave compensation study to be satisfied actual demand. ${ }^{[1]}$

The research object of heave compensation technology is the vertical movement of vessels, which can reduce the impact of heave motion and can ensure the normal operation of offshore operations in case of bad sea conditions. The United States and Norway and other countries start early research on wave compensation technology and have developed more mature products and put them into practical use. However, our country's research on heave compensation technology is still in the stage of theoretical research. It is essential to sort out and classify heave compensation technology to promote the development of China's heave compensation technology and use of marine resources. 


\section{Research status at home and abroad}

Foreign research status. Countries such as Europe and the United States began to focus on heave compensation technology research from the end of the 19th century. So far a series of mature products have been developed. The United States, Norway, and Germany possess the most mature products.

The United States Varco Company is a company specializing in the design and manufacture of wave compensation devices. It can develop targeted products for the needs of customers. It successfully provided a wave compensation device for deep-sea towing operations for the "Roger-Rayefeller" a marine investigation ship of the Scripps Institution of Oceanography, and provided various types of wave compensation systems for the U.S. Navy T-AGS60 marine survey ship. [2]

The Norwegian company Hydarlift is a company specializing in the production of various kinds of cranes, retractable devices, and drilling rigs. It has developed a special automatic wave compensation technology for operations under severe sea conditions, and successfully developed a series of cranes and ROV retractable devices with wave compensator. It is currently the world's most advanced ship crane manufacturer with wave compensation. ${ }^{[3]}$

The Rexroth Bosch Group has successfully developed a RAHC-Active Heave Compensation with Secondary-Controlled Winch Drive based on the secondary control drive technology. Rexroth Bosch Group has successfully developed a secondary hydraulic winch with active wave compensation based on the secondary control drive technology. This kind of winch combines energy recovery, savings, and reuse, and has the advantages of compact structure and low energy consumption. At the same time, it has a variety of compensation modes, which can compensate the \pm 3 m heave motion within 9 s wave period for weights from 5 tons to 500 tons. $^{[4]}$

Research state in China. China's research on heave compensation technology starts late, and it lags behind its foreign counterparts in engineering application. However, after a long period of efforts, it has achieved a lot.

Yang Wenling who works at the Robotics Laboratory of the Shenyang Institute of Automation, Chinese Academy of Sciences developed an active heave compensation system based on the hydraulic retractable winch for underwater robots. Acceleration sensor is used to collect the mother ship's motion signal, and the effect of the mother ship's heave motion on the underwater robot is compensated by controlling the rotation direction and speed of the winch, and an experimental platform is set up to verify the effectiveness of the compensation scheme. The compensation rate reaches $80 \% .{ }^{[5]}$ The team of Professor Lian Lian of Shanghai JiaoTong University developed a passive compensation system for underwater robot systems based on the national 863 key project "4500m deep sea operation system". In this system, two accumulators are connected in series to form a passive compensation system, and the pool simulation experiment proves the effectiveness of the scheme ${ }^{[6]}$. The compensation schemes proposed by the two teams mentioned above adopt active and passive compensation schemes respectively, which are applicable to different applications and provide lessons for the research and development of the heave robot heave compensation system in China.

The team of Ni Jia from Central South University designs a passive heave compensation system based on accumulators for the $5000 \mathrm{~m}$ oceanic polymetallic nodule mining system. They analyze the main factors that affect the compensation effect, and conduct corresponding experiments. The research results show that the load is accessed first. Then the accumulator is 
accessed, and the accumulator obtain a more ideal compensation with the method of segmented pre-charging. ${ }^{[7]}$ Dr. Xiao Ti Bing of Guangdong University of Technology proposes a heave compensation program for deep-sea mining systems that based on speed compensation strategy, and designs the parameters of the compensation system under heavy load conditions, then verifies the effectiveness of the compensation strategy by comparing simulation results with experimental results. $^{[8]}$

Chen Zhangjian of Dalian Maritime University proposes an active and passive compound wave compensation scheme with energy recovery function. In addition to accomplishing the compensation goal, the scheme connects the energy recovery part to the system through the clutch, thereby the energy utilization rate and the economy of the compensation scheme are further improved. The scheme provides a new idea for improving the energy utilization rate. ${ }^{[9]}$

In summary, China has conducted a certain theoretical research on heave compensation technology and has made great progress in applications such as unmanned underwater robots, deep-sea mining systems, and lifting boats. It provides lessons for future heave compensation research, but it has not been able to develop a heave compensation program specifically for ship cranes. The research and application of heave compensation technology is still in its infancy and urgently needs further research and development.

\section{Classification of heave compensation system}

According to different uses, the heave compensation system can be subdivided into deep sea mining heave compensation systems, cabled underwater robot heave compensation systems, drill string heave compensation systems, and ship crane heave compensation systems.

Deep sea mining heave compensation system. Deep-sea mining vessels refer to vessels that are specially used to collect high-value mineral resources such as polymetallic manganese nodules on the seabed. When such a ship is operating in the deep sea, it will produce six degrees of freedom of swinging motion under the influence of ocean wind, waves and currents. And it will make the system generate a huge additional load, which seriously affects the work efficiency, and even causes damage to the piping, leads to complete failure of the system. ${ }^{[10]}$ Therefore, a special heave compensation system is indispensable for deep sea mining systems. It can weaken the impact of the heave motion of deep-sea mining vessels on underwater equipment such as mine pipes, and it is one of the essential key equipment for deep-sea mining operations.

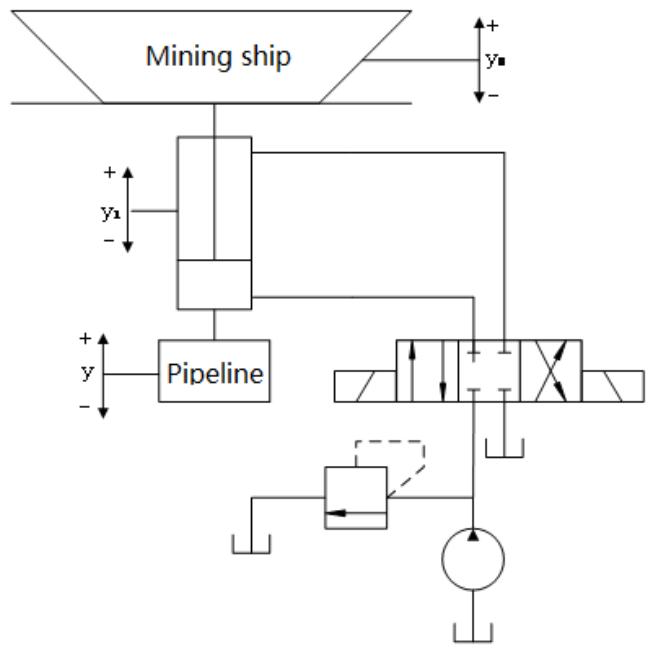

Fig. 1 The working principle of heave compensation system of deep sea mining system

In the deep sea mining heave compensation system shown in Fig. 2 above, the longitudinal displacement of the pipeline is: 


$$
y=y_{0}+y_{1}
$$

In the above formula, $y$ indicates the longitudinal displacement of the pipeline; $y_{0}$ indicates the heave displacement of the mining ship; $y_{1}$ indicates the longitudinal displacement of the compensation cylinder. The control principle is shown in Fig. 2 below.

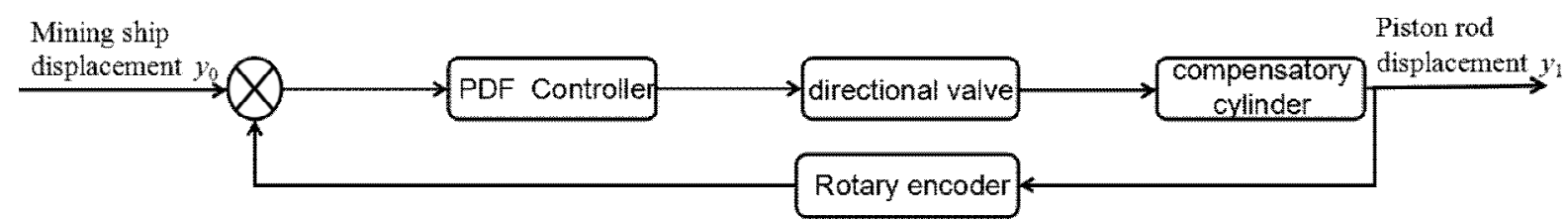

Fig. 2 The control principle of heave compensation system of deep sea mining system

When the heave motion of the mining vessel occurs, the sensor starts to work and captures the hull motion signal and sends it to the controller. The PDF ( Pseudo derivative feedback ) controller calculates and sends a control signal to the electro-hydraulic proportional directional valve to control the hydraulic oil to enter the corresponding chamber of the compensation cylinder to push the piston up and down, so that keep the pipeline relatively stationary with respect to the sea floor so as to achieve the purpose of compensation.

Cable underwater robot heave compensation system. The cabled underwater robot must rely on the umbilical cable to obtain energy and control instructions from the mother ship. Therefore, the mother ship's heave motion will also be transmitted to the underwater robot through the umbilical cable, resulting in violent relative movement between the underwater robot and the repeater. This will have a huge impact on the deployment and safe operation of underwater robots. In severe cases, it will even cause the rupture of the umbilical and cause the loss of underwater robots, leading to serious economic losses.

Currently, the retracting operation of underwater robots is usually completed by a winch, which is a common equipment for a cable underwater robot retracting system. Therefore, a winch device is used to achieve heave compensation, which not only can achieve a large compensation range, but also does not require additional equipment, and it is convenient for layout. ${ }^{[1]}$ The working principle of a typical winch heave compensation system is shown in the figure below.

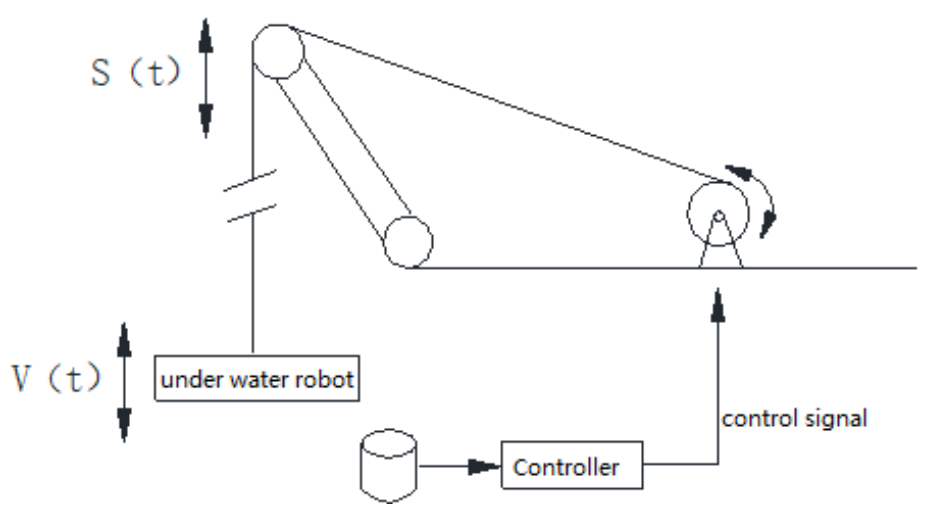

Fig. 3The working principle of heave compensation system of ROV

According to Fig. 3 we can know that:

$\mathrm{v}(\mathrm{t})=w(t)+s(t)$

In the above formula, $\mathrm{v}(t)$ represents the deep motion of the underwater robot; $w(t)$ indicates the winch movement; and $s(t)$ indicates the mother ship's heave motion. If the winch's steering and 
rotation speed can be controlled so that the underwater robot remains relatively stationary with respect to the seabed, then heave compensation is achieved. The control block diagram is shown in Fig. 4.

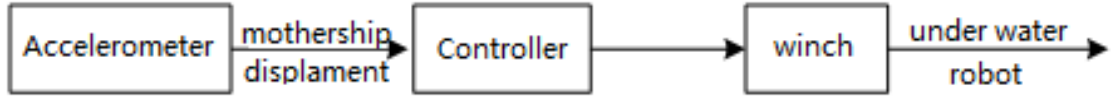

Fig. 4 The control principle of heave compensation system of deep sea mining system

Drill string heave compensation system. When the floating drilling rig is working, a violent heave motion will cause the drill string to reciprocate in the vertical direction, so that the bottom hole drilling pressure will change. In severe cases, the drill bit will get out of the bottom of the well and affect the normal drilling work. Therefore, it is necessary to equip the offshore floating drilling platform with a special heave compensation system. According to the different structural forms, the drill string heave compensation system can be divided into the types of travel vehicle hook type, sky type vehicle, dead rope compensator and winch type. In this paper, the working principle of the common travel hook compensation system is introduced with specific application examples. ${ }^{[12]}$

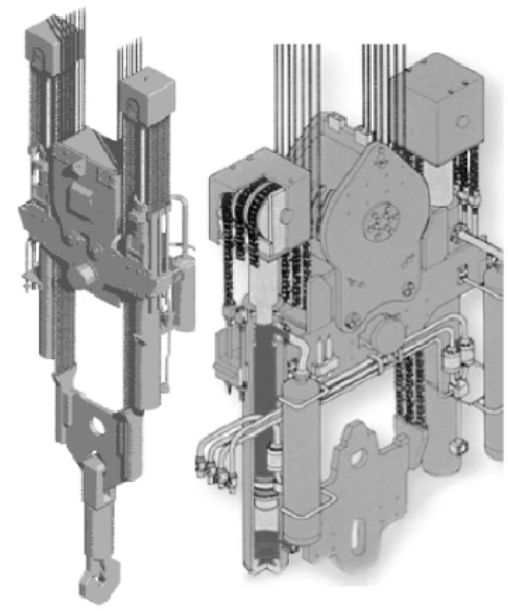

Fig. 5 The tour hook type heave compensation system of drill string

As shown in Fig. 5 above, a double-cylinder cruiser hook-type heave compensation system proposed by Varco company in the United States is one of the most widely used in the world. The system is mainly composed of a traveling vehicle, a compensation cylinder, a large hook, an accumulator, a high-pressure air bottle, and a series of valves that realize control functions. The compensation cylinder is located between the traveling car and the big hook. The cylinder body is connected with the traveling car through the upper frame, and the piston rod is connected with the big hook through the lower frame. The rodless chamber of the cylinder is filled with high-pressure gas, and is connected with the cylinder through a hose. The rod chamber is filled with hydraulic oil and is connected with an accumulator via a hose. The hydraulic oil in the rod chamber withstands the working load of the hook and the drill string. When the drilling platform has a heave motion, it can only drive up and down the cylinder of the compensation cylinder, and the big hook and drill rod do not move, thus compensating the impact caused by the heave motion of the platform.

Ship crane heave compensation system. In severe sea conditions, the safety of lifting operations cannot be guaranteed due to the impact of the ship's heave motion while the ship crane is operating. A large number of engineering practices have proved that the provision of a special heave compensation system can effectively compensate for the impact of ship heave motion on lifting operations. A common ship crane heave compensation device is shown in Fig. 6 . In the heave compensation system as shown in the figure, the heave compensation cylinder 3 , the accumulator 10, the high pressure cylinder 11, and the pulley block constitute a heave compensation unit. The 
lower part of the accumulator is filled with hydraulic oil and communicates with the rodless chamber of the heave compensation cylinder. The upper part is filled with high-pressure gas (usually nitrogen). At this time, the load is fully borne by the hydraulic oil in the rodless chamber of the heave compensating cylinder and the heave compensation function is realized by changing the volume of the high pressure gas at the upper part of the accumulator.

When the hoisting weight moves up with the mothership, the pulling force in the hoisting rope becomes larger and the piston rod is pushed to the left. The hydraulic oil in the rodless chamber is squeezed into the lower chamber of the accumulator under the action of the inertial force of the piston rod, which makes the pressure in the energy device become larger. The high pressure gas in the upper part of the accumulator is pressed into the high pressure gas bottle, and part of the energy is recovered. When the lifting weight moves down with the mother ship, the pulling force in the lifting rope becomes smaller, the piston rod moves to the right, the pressure in the rodless chamber becomes smaller, the high pressure gas in the upper part of the accumulator will expand, and the hydraulic oil will be sent into the rodless chamber. Thereby release part of the energy recovered from the high-pressure gas cylinder, the energy efficiency is improved while achieving the purpose of heave compensation.

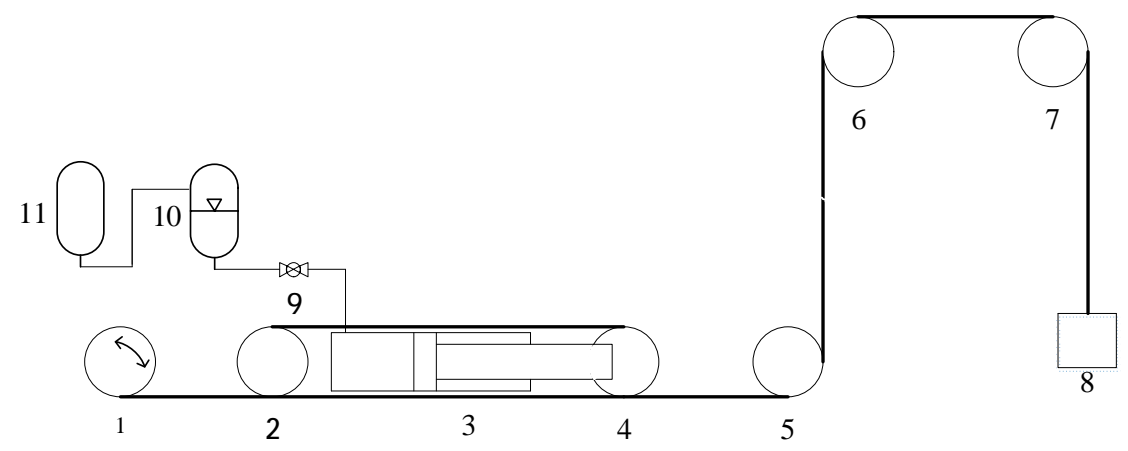

1 ) Lifting winch, 2 ) $、 4$ ) 、 5 ) 、6 )、 7 ) Pulley, 3 ) Heave compensation cylinder、

8 ) Hoist、9 ) Ball valve、10 ) Accumulator、11 ) High pressure gas cylinder

Fig. 6 The working principle of passive heave compensation system of ship crane

\section{Conclusion}

This article collects a large amount of research data, summarizes the current development status of domestic and foreign heave compensation techniques, and classifies heave compensation systems based on different applications. which lays the foundation for the healthy development of China's heaving compensation technology and promotes the emergence of mature products.

\section{Acknowledgment}

This work was financially supported by the Fundamental research funds for the Central Universities (3132014332, 3132015025, 3132016345) and National Science Foundation of China (51779026).

\section{References}

[1] Neupert J, Mahl T, Haessig B, et al. A heave compensation approach for offshore cranes[C]// American Control Conference.IEEE,2008:538-543. 
[2] http://www.nov.com/

[3] Lifting device with automatic wave compensation [J].mechanical and electrical equipment. 2000(06):43-44.

[4] Tang Lei. Research on key technology of heave compensator [D]. Harbin Engineering University, 2012.

[5] Yang Welin, Zhang Zhuying, Zhang Aiqun. Research on active heave compensation system for underwater vehicle [J]. Oceanographic engineering,2007(03):68-72

[6] Lian Lian, MaXiafei, Tao Jun. Research and development of the "hippocampus" 4500 meter ROV system [J]. Naval Architecture and Marine Engineering,2015,31(01):9-12

[7] Ni Jia. Study on parameters design and Simulation of passive heave compensation system in deep sea mining [D]. Central South University,2009.

[8] Xiao Tibing. Research on Intelligent heave compensation system for deep-sea mining equipment [D]. Guangdong University of Technology,2004.

[9] Chen Zhangjian. Design and study of wave compensation actuator [D]. Dalian Maritime University,2013

[10] Sharma R. Deep-Sea Mining: Economic, Technical, Technological, and Environmental Considerations for Sustainable Development[J].Marine Technology Society Journal, 2011,45(45):28-41.

[11] Miao HU, Zhu M. Design of Constant-Tension Deploying and Retracting Winch for Optic-Electrical Composite Cable of ROV[J]. Optical Fiber \& Electric Cable \& Their Applications, 2015

[12] Hu Xiaodong. Design of lifting and sinking compensation system for floating offshore drilling drill string [D]. China University of Geosciences, 2013. 